\title{
Arborização urbana do bairro Centro do município de Cataguases, MG
}

Luana de Paula ${ }^{1}$

Matheus Sebastião Silva Duarte ${ }^{2}$

Renata Barreto Tostes ${ }^{3}$

Paulo Roberto de Oliveira Junior ${ }^{4}$

Samuel de Souza Ruback 5

\section{Resumo}

A arborização urbana é de suma importância para a qualidade de vida da população. O inventário da arborização fornece informações necessárias para desenvolver um plano de manejo adequado, permitindo conhecer as condições da arborização. Objetivou-se com este trabalho quantificar e qualificar a arborização urbana do bairro centro da cidade de Cataguases, onde realizamos levantamentos qualitativos e quantitativos das espécies, sendo inventariados 1.927 indivíduos pertencentes a 39 espécies e 21 famílias botânicas. Destas, 56,41\% são Exóticas, 15,38\% são Nativa Regional e $28,20 \%$ são Nativa não regional. A espécie Licania tomentosa (oiti) correspondeu a $77,99 \%$ do total de indivíduos amostrados; as demais 38 espécies representaram apenas 22,1\%. A copa apresentou $97 \%$ de interferência na fiação elétrica. Diante desses dados, fica evidente a falta de planejamento da arborização urbana do bairro Centro do município de Cataguases que, apesar de ser muito arborizada, carece de planejamento.

Palavras-Chave: Arborização de vias públicas. Espécies. Conflitos. Licania tomentosa.

\section{Introdução}

A arborização urbana é de suma importância para a qualidade de vida da população, atuando diretamente sobre a amenização climática, a qualidade do ar, o nível de ruídos, a paisagem, além de constituir refúgio e alimento à fauna (SILVA et al., 2007; LANGOWSKI, 2001). Note-se que a arborização urbana contribui tanto com a melhora da qualidade de vida da população como também exerce função na conservação da biodiversidade no perímetro urbano (RICHTER et al., 2012)

Segundo Miller (1998), para que a arborização urbana produza efeitos positivos, deveria ser implantado em todas as cidades, independentemente do seu tamanho, um plano diretor da arborização, que consiste no planejamento, seleção, estabelecimento, manutenção e remoção de árvores nas vias públicas. Esse planejamento e manejo da arborização contribuem para diminuir os conflitos

\footnotetext{
$1 \quad$ Faculdades Integradas de Cataguases, Acadêmica do Curso de Ciências Biológicas. E-mail: lunaraicca@hotmail.com. Romualdo Menezes, 701, Bairro Menezes, Cataguases, MG, Brasil - CEP 701 - 36773-084.

2 Faculdades Integradas de Cataguases, Acadêmico do Curso de Ciências Biológicas. E-mail: mateus.2012@hotmail.com. Romualdo Menezes, 701, Bairro Menezes, Cataguases, MG, Brasil - CEP 701 - 36773-084.

3 Universidade do Estado de Minas Gerais - unidade Ubá, profa. MSc. Designada. E-mail: rtostes@hotmail.com. Avenida Olegário Maciel, 1427, Bairro Industrial, Ubá, MG, Brasil - CEP 36500-000

$4 \quad$ Faculdades Integradas de Cataguases, Acadêmico do Curso de Ciências Biológicas. E-mail: oliveirajunior@hotmail.com. Romualdo Menezes, 701, Bairro Menezes, Cataguases, MG, Brasil - CEP 701 - 36773-084.

5 Faculdades Integradas de Cataguases, Acadêmico do Curso de Ciências Biológicas. E-mail: samuel_ruback@hotmail.com. Romualdo Menezes, 701, Bairro Menezes, Cataguases, MG, Brasil - CEP 701 - 36773-084
} 
no futuro entre as árvores e os equipamentos e edificações urbanas (PIVETA; SILVA FILHO, 2002).

O inventário quantitativo e qualitativo da arborização urbana é o primeiro passo para construir o plano diretor da arborização de uma cidade, pois ele permite um melhor planejamento da arborização, objetivando melhorar a qualidade de vida na cidade bem como contribuir para a preservação da diversidade local (KURIHARA et al., 2005; MILLER, 1998).

Uma arborização mal planejada faz que a população passe a não querer árvores em suas ruas, pelos diversos problemas que ela provoca, principalmente quando se utilizam espécies inadequadas, que estabelecem conflitos com a linha de transmissão de energia e de telefonia, podendo também danificar calçadas e muros das residências bem como provocar queda excessiva de folhas e flores (RODRIGUES, et al., 2010; ROPPA et al., 2007).

O município de Cataguases apresenta um crescimento desordenado, em decorrência de um expressivo crescimento demográfico e territorial, o que vem provocando a degradação do meio natural nos últimos anos. Somado a esse fator, o município apresenta, ainda, temperaturas médias elevadas ao longo do ano. Essas informações demonstram a necessidade de se planejar uma arborização que contribua para uma melhor qualidade de vida da população.

Objetivou-se, com este trabalho, realizar o levantamento das árvores urbanas da cidade de Cataguases-MG, com identificação das espécies nativas e exóticas presentes e de suas interferências no espaço urbano, a fim de fornecer dados ao poder público para elaboração de um Plano diretor de Arborização Urbana.

\section{Material e Métodos}

O município de Cataguases localiza-se no domínio da Mata Atlântica, na região da Zona da Mata Mineira, entre as coordenadas $21^{\circ} 23^{\prime} 20^{\prime \prime}$ S, 42 $41^{\prime} 49^{\prime \prime}$ ' W. Possui uma área com 482,33 $\mathrm{km}^{2}$, e é limitado pelos municípios de Leopoldina, Santana de Cataguases, Dona Euzébia, Itamarati de Minas e Miraí. Sua população é composta por 69.757 habitantes (IBGE, 2014).

A temperatura média anual é de $24,5^{\circ} \mathrm{C}$ (Prefeitura Municipal de Cataguases), com médias máximas e mínimas de $31^{\circ} \mathrm{C}$ e $18^{\circ} \mathrm{C}$, respectivamente. 0 índice pluviométrico anual no município é de $1.564 \mathrm{~mm}$, com as chuvas concentradas no período de outubro a março.

O presente trabalho foi realizado no bairro Centro do município de Cataguases (Figura 1), que é o maior bairro da cidade, com 56 ruas e 10 praças. A escolha desse bairro se deu por ser a região com a maior concentração populacional da cidade e ser a mais arborizada. 


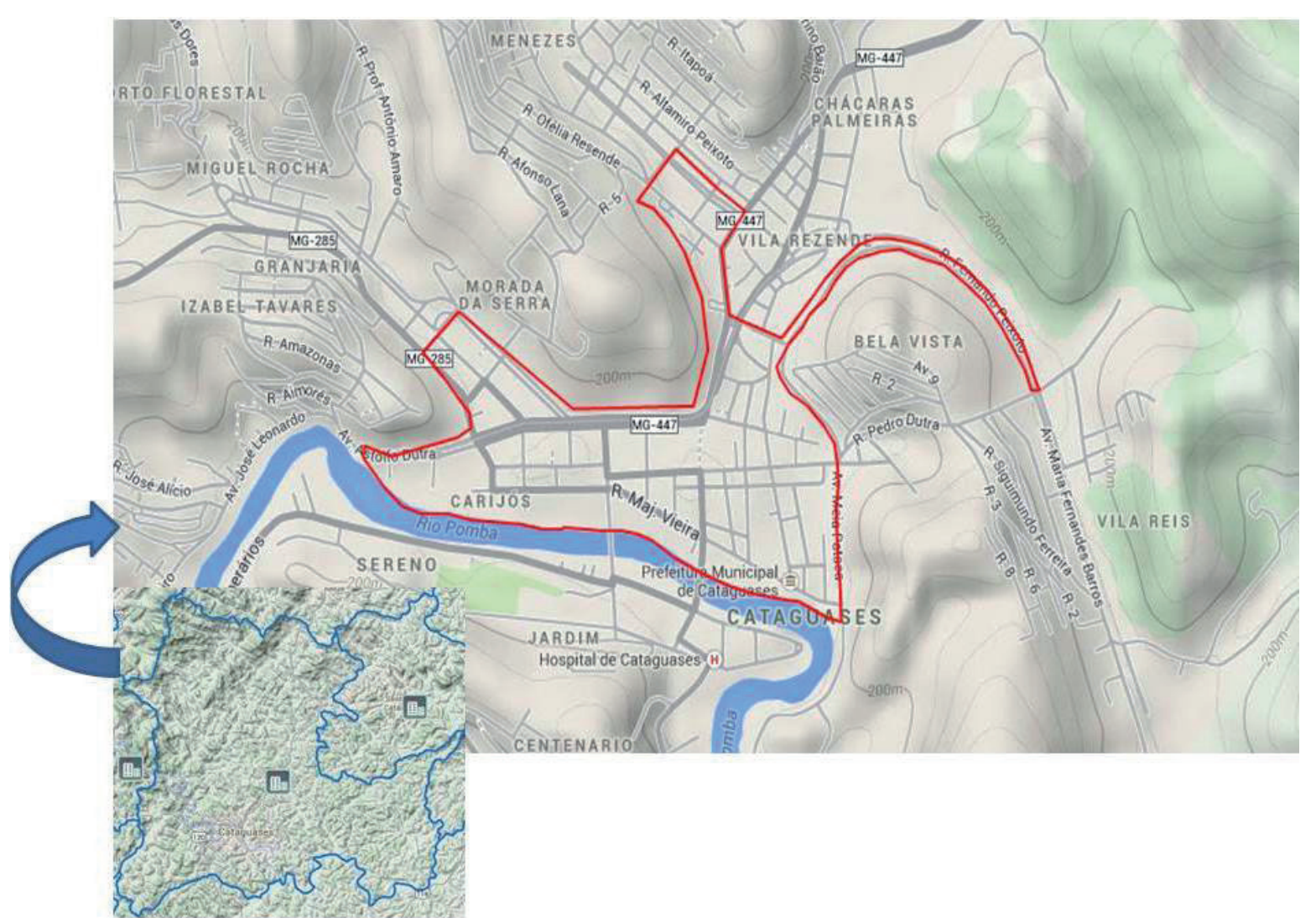

Figura 1. Delimitação bairro Centro do Município de Cataguases - área estudada.

Fonte: Google Imagens

A coleta dos dados dos indivíduos arbóreos foi realizada no período de fevereiro a novembro de 2012, por meio de caminhadas pelas ruas e praças do centro. Uma ficha de campo foi elaborada com as seguintes informações: Rua; Nome comum e científico; Circunferência na Altura do Peito (CAP - cm); Altura Total (m); Interferência de copa, fuste, raiz nas casas, placas de trânsito, fiação elétrica e pedestre, e Observações.

O levantamento das interferências ocasionadas pelas árvores foi realizado visualmente e as interferências foram apontadas: se eram pela copa e/ou fuste e/ou raiz. Todos os indivíduos foram fotografados (utilizando máquina digital) para facilitar a identificação, compreensão e melhor visualização dos dados levantados.

A identificação das espécies foi realizada in loco quando possível, por meio de metodologia usual taxonômica ou de consulta a bibliografia especializada (CARVALHO 2006; LORENZI, 2004; LORENZI et al., 2003; LORENZI et al., 2002). As espécies não identificadas foram herborizadas e encaminhadas a especialistas. O sistema de classificação das espécies utilizado no trabalho foi o sistema APG III (2009). A frequência relativa de cada espécie foi calculada pela razão entre o número de indivíduos da espécie e o número total de indivíduos inventariados nas vias públicas do município.

Quanto à origem, as espécies identificadas foram classificadas em Nativa regional (espécies originárias dos ambientes de Floresta Estacional Semidecidual), Nativa não regional (ocorre em outras tipologias vegetais do Brasil) e Exótica (espécie oriunda de ecossistemas de outros países). 


\section{Resultados e Discussão}

Foram inventariados 1.927 indivíduos pertencentes a 39 espécies e 21 famílias botânicas, sendo 228 indivíduos nas praças pertencentes a 26 espécies e 1.699 indivíduos nas ruas pertencentes a 29 espécies (Tabela 1 ).

As famílias que apresentaram maior número de indivíduos foram Chrysobalanaceae (1.503 indivíduos), Leguminosae-caesalpinioideae (164 indivíduos), Arecaceae (84 indivíduos), Magnoliaceae (53 indivíduos), Moraceae (27 indivíduos) e Bignoniaceae (24 indivíduos). Essas mesmas famílias também foram dominantes em trabalhos realizados em outros município, como em Uchôa-SP (STRANGHETTI; SILVA, 2010), Carlinda-MS, Alta Floresta-MS e Nova Monte Verde-MS (ALMEIDA; RONDON NETO, 2010) e em Goianira-GO (MIRANDA et al., 2012).

Tabela 1. Lista com a composição das espécies arbóreas das praças e ruas inventariadas separadas por nome científico, nome comum, família, CAP médio, Altura média e Frequência Relativa.

\begin{tabular}{|c|c|c|c|c|c|}
\hline Nome Científico & Nome Comum & Família & CAP médio & Altura Média & FR \\
\hline \multicolumn{6}{|c|}{ PRAÇA } \\
\hline Licania tomentosa & Oiti & Chrysobalanaceae & 137,7 & 6,3 & 43,42 \\
\hline $\begin{array}{l}\text { Caesalpinia } \\
\text { peltophoroides }\end{array}$ & Sibipiruna & $\begin{array}{l}\text { Leguminosae- } \\
\text { caesalpinioideae }\end{array}$ & 88,6 & 7,9 & 21,92 \\
\hline Michelia champaca & Magnólia & Magnoliaceae & 82,3 & 4,8 & 5,70 \\
\hline Livistona chinensis & Palmeira leque & Arecaceae & 73,4 & 10,3 & 4,38 \\
\hline Ficus bejamina & Ficus & Moraceae & 470,5 & 13,6 & 3,94 \\
\hline Tabebuia Chrysotricha & Ipê amarelo & Bignoniaceae & 57,1 & 5,5 & 3,50 \\
\hline Tabebuia avellanedae & Ipê rosa & Bignoniaceae & 97,2 & 7,9 & 2,19 \\
\hline Mangifera indica & Mangueira & Anacardiaceae & 295,5 & 13,2 & 1,75 \\
\hline Myrciaria jaboticaba & Jaboticaba & Myrtaceae & 77,6 & 5,6 & 1,31 \\
\hline Peltophorum dubium & Canafístula & $\begin{array}{l}\text { Leguminosae- } \\
\text { caesalpinioideae }\end{array}$ & 131,3 & 10 & 1,31 \\
\hline Albizia lebbeck & Ébano oriental & $\begin{array}{l}\text { Leguminosae- } \\
\text { mimosoideae }\end{array}$ & 88,5 & 6,2 & 0,87 \\
\hline Araucaria columnaris & Pinheiro de natal & Araucariaceae & 21 & 4,2 & 0,87 \\
\hline Clitoria fairchildiana & Sombreiro & $\begin{array}{l}\text { Leguminosae- } \\
\text { caesalpinioideae }\end{array}$ & 171 & 10 & 0,87 \\
\hline Delonix regia & Flamboyant & $\begin{array}{l}\text { Leguminosae- } \\
\text { caesalpinioideae }\end{array}$ & 231,5 & 12,5 & 0,87 \\
\hline Myrtaceae sp. & Myrtaceae & Myrtaceae & 154,5 & 7,5 & 0,87 \\
\hline Roystonea oleracea & Palmeira & Arecaceae & 182,5 & 15,5 & 0,87 \\
\hline Senna multijuga & Aleluia & $\begin{array}{l}\text { Leguminosae- } \\
\text { caesalpinioideae }\end{array}$ & 53,5 & 4 & 0,87 \\
\hline Syzygium malaccense & Jambo & Myrtaceae & 178,5 & 14 & 0,87 \\
\hline Averrhoa carambola & Carambola & Oxalidaceae & 115 & 9 & 0,43 \\
\hline Caesalpinia echinata & Pau Brasil & $\begin{array}{l}\text { Leguminosae- } \\
\text { caesalpinioideae }\end{array}$ & 44 & 7 & 0,43 \\
\hline Cassia fistula & Cássia & $\begin{array}{l}\text { Leguminosae- } \\
\text { caesalpinioideae }\end{array}$ & 93 & 5,5 & 0,43 \\
\hline Pouteria torta & Abiu & Sapotaceae & 92 & 13 & 0,43 \\
\hline Schinus polygama & Aroeira & Anacardiaceae & 47 & 7 & 0,43 \\
\hline Tabebuia roseo-alba & Ipê branco & Bignoniaceae & 37 & 7 & 0,43 \\
\hline Tamarindus indica & Tamarindo & $\begin{array}{l}\text { Leguminosae- } \\
\text { caesalpinioideae }\end{array}$ & 493 & 15 & 0,43 \\
\hline Terminalia catappa & Amendoeira & Combretaceae & 291 & 18 & 0,43 \\
\hline
\end{tabular}




\begin{tabular}{|c|c|c|c|c|c|}
\hline Nome Científico & Nome Comum & Família & CAP médio & Altura Média & FR \\
\hline \multicolumn{6}{|c|}{ RUA } \\
\hline Licania tomentosa & Oiti & Chrysobalanaceae & 124,8 & 5,7 & 82,63 \\
\hline Roystonea oleracea & Palmeira & Arecaceae & 175,5 & 7,9 & 4,17 \\
\hline $\begin{array}{l}\text { Caesalpinia } \\
\text { peltophoroides }\end{array}$ & Sibipiruna & $\begin{array}{l}\text { Leguminosae- } \\
\text { caesalpinioideae }\end{array}$ & 142,7 & 8,3 & 3,70 \\
\hline Michelia champaca & Magnólia & Magnoliaceae & 111,1 & 5,15 & 2,35 \\
\hline Delonix regia & Flamboyant & $\begin{array}{l}\text { Leguminosae- } \\
\text { caesalpinioideae }\end{array}$ & 138,3 & 6,6 & 1,17 \\
\hline Ficus bejamina & Ficus & Moraceae & 241,8 & 7,8 & 0,82 \\
\hline Dillenia indica & Árvore do dinheiro & Dilleniaceae & 168,3 & 6,1 & 0,70 \\
\hline Pachira aquatica & Cacau falso & Malvaceae & 50 & 5,2 & 0,64 \\
\hline Tabebuia Chrysotricha & Ipê amarelo & Bignoniaceae & 30,8 & 5,1 & 0,52 \\
\hline Terminalia catappa & Amendoeira & Combretaceae & 98,5 & 8,8 & 0,47 \\
\hline Cassia grandis & Cássia rosa & $\begin{array}{l}\text { Leguminosae- } \\
\text { caesalpinioideae }\end{array}$ & 77,6 & 6,3 & 0,47 \\
\hline Bauhinia variegata & Pata de vaca & $\begin{array}{l}\text { Leguminosae- } \\
\text { caesalpinioideae }\end{array}$ & 78,1 & 6,6 & 0,41 \\
\hline Lisgustrum Iucidum & Alfeneiro & Oleaceae & 133 & 6,7 & 0,29 \\
\hline Cassia fistula & Cássia & $\begin{array}{l}\text { Leguminosae- } \\
\text { caesalpinioideae }\end{array}$ & 60,3 & 7,3 & 0,17 \\
\hline $\begin{array}{l}\text { Ficus bejamina } \\
\text { variegata }\end{array}$ & Ficus variegata & Moraceae & 47 & 6 & 0,17 \\
\hline Psidium guajava & Goiabeira & Myrtaceae & 39,6 & 4,6 & 0,17 \\
\hline Mangifera indica & Mangueira & Anacardiaceae & 211,3 & 9,3 & 0,17 \\
\hline Peltophorum dubium & Canafístula & $\begin{array}{l}\text { Leguminosae- } \\
\text { caesalpinioideae }\end{array}$ & 130,5 & 8 & 0,11 \\
\hline Swietenia macrophylla & Mogno & Meliaceae & 107 & 8 & 0,11 \\
\hline Araucaria columnaris & Pinheiro de natal & Araucariaceae & 46 & 7 & 0,11 \\
\hline Pouteria torta & Abiu & Sapotaceae & 199 & 8 & 0,05 \\
\hline Senna multijuga & Aleluia & $\begin{array}{l}\text { Leguminosae- } \\
\text { caesalpinioideae }\end{array}$ & 228 & 9 & 0,05 \\
\hline Bougainvillea glabra & Bougainvillea & Nyctaginaceae & 126 & 7 & 0,05 \\
\hline Ficus enormis & Figueira & Moraceae & 360 & 13 & 0,05 \\
\hline Tabebuia avellanedae & Ipê rosa & Bignoniaceae & 150 & 12 & 0,05 \\
\hline Syzygium malaccense & Jambo & Myrtaceae & 120 & 9 & 0,05 \\
\hline Tibouchina granulosa & Quaresmeira & Melastomataceae & 36 & 5 & 0,05 \\
\hline Salix babylonica & Salgueiro chorão & Salicaceae & 22 & 4 & 0,05 \\
\hline Phoenix roebelinii & Tamereira de jardim & Arecaceae & 85 & 2 & 0,05 \\
\hline
\end{tabular}

Fonte: Elaboração dos autores

As espécies mais frequentes nas praças foram Licania tomentosa (oiti) $(43,42 \%)$, Caesalpinia peltophoroides (21,92\%), Michelia champaca (5,70\%), Livistona chinensis (4,38\%), Ficus bejamina (3,94\%), Tabebuia Chrysotricha (3,50\%). Essas 6 espécies juntas representaram 82,86\% do total de indivíduos identificados nas praças (Figura 2). Já nas ruas, as 6 espécies mais frequentes foram Licania tomentosa (oiti) (82,63\%), Roystonea oleracea $(4,17 \%)$, Caesalpinia peltophoroides $(3,70 \%)$, Michelia champaca $(2,35 \%)$, Delonix regia $(1,17 \%)$, Ficus bejamina $(0,82 \%)$, correspondendo a $94,84 \%$ dos indivíduos identificados nas ruas.

Os dados levantados demonstram a dominância na paisagem urbana do centro de Cataguases de uma única espécie, a Licania tomentosa, que apresentou 1.503 indivíduos no total, sendo a espé- 
cie mais frequente no centro (77,99\%). A dominância de poucas espécies na arborização de cidades de médio e pequeno porte no Brasil tem sido constatada em diversos levantamentos já realizados, como em Chapada-RS, onde sete espécies representaram 70,54\% da arborização presente (GAUER, 2012); em Irati-PR, onde 55\% do inventário foi representado por três espécies (COLTRO; MIRANDA, 2007); em Campina Grande-PB, onde quinze das 132 espécies levantadas representam 83\% do levantamento arbóreo; em Cachoeira do Sul-RS, onde dez espécies perfizeram um total de 54,2\% de um total de 132 indivíduos (LINDENMAIER; SANTOS, 2008).

Silva et al., (2007) afirmam que o ideal é que cada espécie represente entre $12 \%$ e 15\% do total de indivíduos presentes na arborização urbana. A dominação de uma única espécie na paisagem urbana deixa a cidade vulnerável quanto à ocorrência de eventos, como doenças e pragas, que poderia levar a um grande número de morte das árvores do município. Esta situação foi vivenciada na cidade de Jaboticabal-SP, onde Graziano (1987) mostrou que 43\% da arborização eram representadas por uma única espécie, Nectandra saligna. Poucos anos depois, seus indivíduos foram atacados por broca, resultando em uma grande diminuição no número de indivíduos que passou de $43 \%$ para menos de $8 \%$ na arborização urbana (SILVA FILHO, 2002).

Quanto à origem das espécies, $22(56,41 \%)$ das espécies encontradas são classificadas como Exótica, 6 (15,38\%) são classificadas como Nativa regional e 11 (28,30\%) são classificadas como Nativa não regional (Figuras 3 e 4). Quando essa classificação é realizada em relação ao número de indivíduos, fica mais evidente que na arborização de Cataguases predominam indivíduos arbóreos não pertencentes à vegetação nativa regional, visto que 250 (13\%) são classificados como Exótico, 1.521 (79\%) são classificados como Nativo não regional e 156 (8\%) são classificados como Nativo regional (Figuras 2 e 3).

Quando se analisa separadamente a origem das espécies das praças e das ruas, não se observa grande diferença entre esses espaços urbanos. Em ambos, o número de Exótica somado ao número de Nativa não regional é maior que o de Nativa regional, correspondendo a 56,75\% das espécies encontradas nas praças e $56,49 \%$ das espécies encontradas nas ruas. Essa condição se altera quando avaliada pelo número de indivíduos, pois, na praça, 67,54\% dos indivíduos são Exóticos e Nativos não regionais, e, nas ruas, 95,17\%. De acordo com Gonçalves e Paiva (2004), a utilização de poucas espécies na arborização urbana de uma cidade se dá pela ausência de estudos sobre as espécies regionais e o ambiente urbano, bem como pela ausência de uma legislação específica para o planejamento da arborização na cidade. 


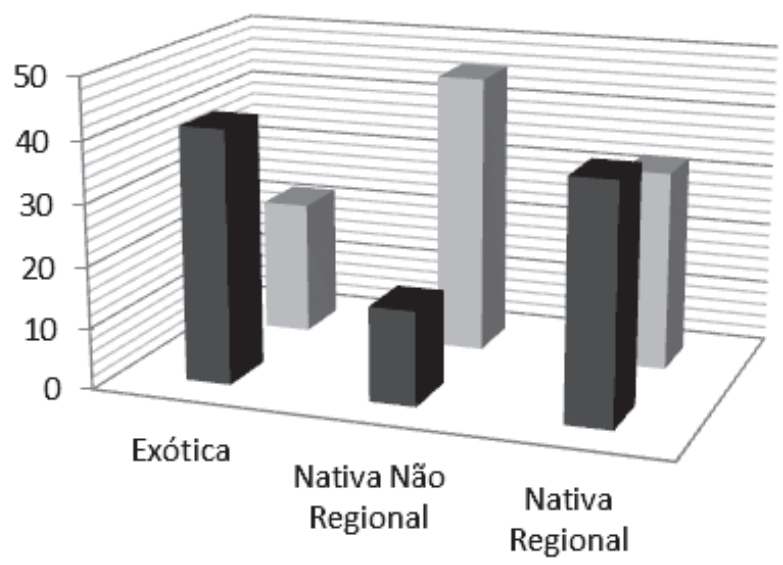

número de Espécies

Número de Indivíduos

Figura 2. Classificação das espécies e indivíduos em Exótica, Nativa Não Regional e Nativa Regional das Praças do Bairro Centro de Cataguases, MG.

Fonte: Elaboração dos autores

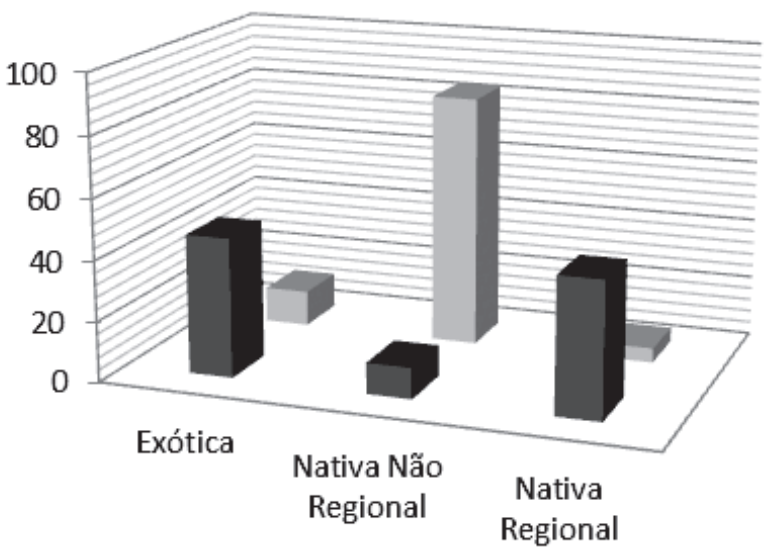

- Número de Espécies

Número de Indivíduos

Figura 3. Classificação das espécies e indivíduos em Exótica, Nativa Não Regional, Nativa Regional e Exótica das Ruas do Bairro Centro de Cataguases, MG.

Fonte: Elaboração dos autores

É de grande importância o uso de espécies nativas na arborização urbana, pois elas apresentam maior resistência a pragas e doenças, permitem a criação de um banco genético ex-situ e oferecem muitos benefícios para a fauna nativa, como fonte de abrigo e alimento (BIONDI; LEAL, 2008; BRUN et al., 2007). Com apenas $8 \%$ de indivíduos arbóreos Nativo da região, a arborização de Cataguases pode não estar contribuindo de forma sistemática para a preservação da biodiversidade local.

Foram encontradas seis espécies de frutíferas comestíveis pelo homem e outros animais: Pouteria torta (abiu), Averrhoa carambola (carambola), Psidium guajava (goiaba), Myrciaria jaboticaba (jaboticaba), Syzygium malaccense (jambo), Mangifera indica (manga). A existência dessas espécies se deve àa participação espontânea da população na composição da arborização urbana. A utilização 
de espécies frutíferas na arborização urbana é recomendada por atrair a fauna ao espaço urbano, aumentando a diversidade. Contudo, devem-se evitar frutos grandes e carnosos que podem trazer perigo à população ou que ocasionem danos aos veículos (CEMIG, 2011).

Ao analisar a interferência que as árvores provocam no bairro centro, verificou-se que 79,6\% dos indivíduos inventariados provocam alguma interferência (Figura 4): 865 indivíduos interferem na rede elétrica, 715,, nas casas, 66 interferem na sinalização de trânsito, 34 na iluminação pública e 10 indivíduos interferem no tráfego de pedestres. Somente 3 indivíduos interferem no tráfego de veículos e 766 indivíduos não causam nenhuma interferência. Essa alta taxa de interferência ocorre pelo fato de a arborização no bairro centro ser predominada por Licania tomentosa, uma espécie de médio a grande porte, que alcança facilmente entre 15 e 20 metros de alturas (LORENZI, et al., 2000).

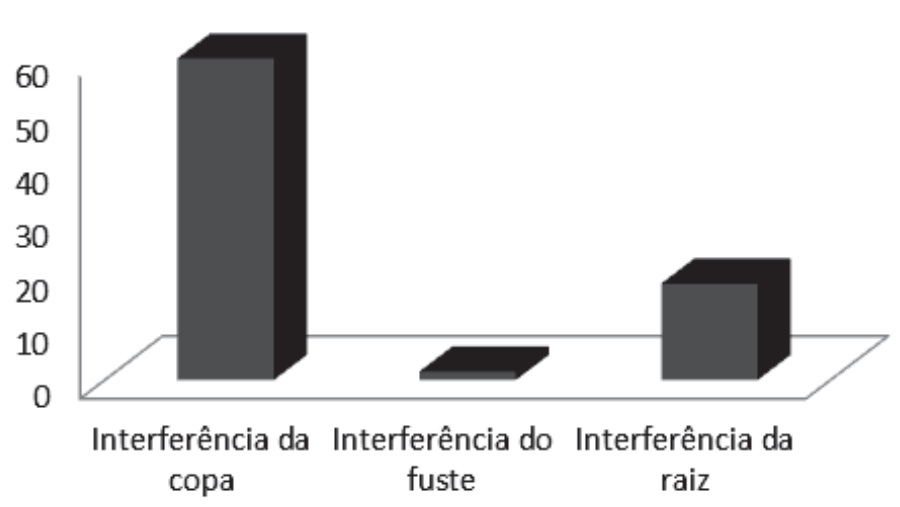

Figura 4. Porcentagem de interferência dos indivíduos inventariados no Bairro Centro de Cataguases. Fonte: Elaboração dos autores

Diversos trabalhos realizados sobre percepção ambiental com pessoas de diversas cidades, com foco na arborização urbana, vêm demonstrando que uma arborização mal planejada na cidade passa uma ideia negativa da arborização, em vez de positiva, em decorrência dos conflitos que ocasiona com os aparatos urbanos, como fios de eletricidade e iluminação pública, bem como também as casas dos moradores. Nesses trabalhos, a população reconhece a importância da arborização, contudo salienta as desvantagens em função das inferências (GROS et al., 2012; RODRIGUES et al., 2010; MALAVASI; MALAVASI, 2001).

Para diminuir essa alta interferência da arborização na fiação elétrica e nas casas, a operadora de energia e a prefeitura realizam podas drásticas no final do inverno, quando retiram quase completamente a copa. Essas podas não solucionam o problema de convivência entre as árvores e os equipamentos urbanos no bairro centro de Cataguases, uma vez que as árvores apresentam rebrota em direção à fiação e às casas no período da chuva, sendo necessárias novas podas em um curto período de tempo.

Esses dados são reforçados quando se analisa a estrutura vertical, visto que $10 \%$ dos indivíduos possuem até 5 metros, 77\% possuem entre 5 e 10 metros e 13\% possuem acima de 10 metros, demostrando que a maioria dos indivíduos de Licania tomentosa tem sua altura controlada por podas.

As podas podem deixar os indivíduos vulneráveis a doenças, pois a parte da planta onde foi realizado o corte fica propícia à entrada de patógenos até que a planta cicatrize (BIONDI, 2008). Segundo os dados apresentados por uma concessionária de energia (ELETROPAULO, 1995), o número de árvores que morrem após as podas é alto, chegando a $27,45 \%$ dos indivíduos podados. Para 
Velasco (2003), não é a poda em si que define a presença ou não de doenças, mas sim o modo como ela é realizada, a forma, o ângulo e a orientação do corte.

Conflitos entre arborização urbana e fiação elétrica vêm sendo retratados há muito tempo em diversos trabalhos. A maioria deles apresenta como soluções o plantio de espécies arbóreas de pequeno a médio porte sob a fiação, além da substituição da rede elétrica convencional pela compacta, com o intuito de diminuir as podas drásticas (LINDENMAIER; SOUZA; 2014; ALMEIDA; BARBOSA, 2010; MARECK, 2008; VELASCO, 2003). Contudo, Castro (2002) salienta que mesmo as espécies de pequeno a médio porte podem atingir a fiação elétrica a médio e longo prazo, dependendo da espécie e das condições do solo. Com isso, espécies de grande porte devem ser também indicadas para plantio sob a rede elétrica, desde que se realize poda de condução ao longo dos anos nos indivíduos.

Os dados levantados demonstram a falta de planejamento no viveiro de mudas do município de Cataguases, por não possuir uma diversidade de espécies de árvores, o que poderia manter a diversidade de espécies na paisagem urbana, garantido assim o máximo de proteção contra pragas e doenças, a fim de evitar futuros problemas para a arborização. Essa falta de planejamento pode ser confirmada também pelo alto índice de interferência que os indivíduos arbóreos provocam nos aparatos urbanos, evidenciando um manejo inadequado por parte da Prefeitura.

Para um adequado planejamento da arborização, devem-se conhecer as características particulares de cada espécie e seu comportamento nas condições ambientais em que serão inseridas (PIVETTA; SILVA FILHO, 2002), para que se evitem alta taxa de interferência e podas drásticas nas árvores.

\section{Conclusões}

Apesar de o bairro centro de Cataguases ser muito arborizado, ele não foi planejado, uma vez que uma única espécie, Licania tomentosa (oiti), dominou o inventário, correspondendo a 77,99\% dos indivíduos amostrados. A maioria desses indivíduos sofre podas drásticas por causar alta taxa de interferência, 79,6\%, principalmente na fiação elétrica e iluminação pública.

A alta porcentagem de indivíduos arbóreos não pertencentes à vegetação nativa regional evidencia que a arborização urbana não vem contribuindo para a preservação da biodiversidade local.

A partir dos dados encontrados no Bairro Centro de Cataguases, conclui-se que se faz necessária a elaboração de um plano diretor de arborização, como forma de buscar um melhor planejamento da arborização urbana de toda a cidade, visando ao equilíbrio ecológico entre as espécies arbóreas e a um manejo mais adequado por parte da prefeitura e da empresa fornecedora de energia.

\section{Urban forestry from the city center of Cataguases, MG}

\section{Abstract}

The urban forestry is paramount to the quality of life. The inventory of trees provides information needed to develop an adequate management plan, allowing to know the conditions of afforestation. The objective of this study was to quantify and qualify the urban greening downtown neighborhood of Cataguases, where we perform qualitative and quantitative surveys of the species, being inventoried 1,927 individuals belonging to 39 species and 21 botanical families. Of these, $56.41 \%$ are exotic, are $15.38 \%$ and $28.20 \%$ Regional Native regional are not native. The Licania tomentosa (oiti), spe- 
cies accounted for $77.99 \%$ of the total sampled, the remaining 38 species accounted for $22.1 \%$. The canopy had $97 \%$ interference in the electrical wiring. Given these data it is evident the lack of planning of urban greening Center neighborhood in the municipality of Cataguases, which despite being heavily wooded, its afforestation was not well planned.

Keywords: Forestry public roads. Species. Risks. Licania tomentosa.

\section{Referências}

APG (Angiosperm Phylogeny Group) III. An update of the Angiosperm Phylogeny Group classification for the orders and families of flowering plants: APG III. Botanical Journal of the Linnean Society, v.161, n.2, p.105-121, 2009.

ALMEIDA, D. N.; RONDON NETO, R. M. Análise da arborização urbana em três cidades da região norte do estado de Mato Grosso. Acta Amazonica, v.40, n.4, p.647-656, 2010.

ALMEIDA, J. R. de; BARBOSA, C. G. Diagnóstico da arborização urbana da cidade de Cacoal-RO. Revista da Sociedade Brasileira de Arborização Urbana, Piracicaba, v.5, n.1, p.61-81, 2010.

BIONDI, D.; LEAL, L. Caracterização das plantas produzidas no Horto Municipal da Barreirinha Curitiba / PR. Revista da Sociedade Brasileira de Arborização Urbana, Piracicaba, v.3, n.2, p.20-36, 2008.

BRUN, F. G. K.; LINK, D.; BRUN, E. J. O emprego da arborização na manutenção da biodiversidade de fauna em áreas urbanas. Revista da Sociedade Brasileira de Arborização Urbana, Piracicaba, v.2, n.1, p.117-127, 2007.

BRUN, F. G. K.; LONGHI, S. J.; BRUN, E. J. Estudo da percepção da população de vilas do Bairro Camobi, Santa Maria - RS sobre a arborização urbana. Revista de Estudos Ambientais, Itajaí, v.11, n.1, p.6-21, 2009.

BRUN, E. J. O emprego da arborização na manutenção da biodiversidade de fauna em áreas urbanas. Revista da Sociedade Brasileira de Arborização Urbana, Piracicaba, v.2, n.1, p.117-127, 2007.

CARVALHO, P. E. R. Espécies arbóreas brasileiras. 1.ed. Brasília: Embrapa Informação Tecnológica, 2006, 627 p.

CASTRO, N. S. de. Os macacos e a arborização urbana. Boletim Informativo - Revista da Sociedade Brasileira de Arborização Urbana, Piracicaba, v.10, n.1, p.6-7, 2002.

COMPANHIA ENERGÉTICA DE MINAS GERAIS - CEMIG. Manual de arborização. Belo Horizonte-MG: Cemig/Fundação Biodiversitas, 2011. 40p.

COLTRO E. M.; MIRANDA G. M. Levantamento da arborização urbana pública de Irati - PR e sua influência na qualidade de vida de seus habitantes. Revista Eletrônica Lato Sensu, Belém, v. 2, n.1, p.27-48, 2007.

ELETROPAULO. Guia de planejamento e manejo da arborização urbana. São Paulo: Eletropaulo; CESP; CPFL, 1995. 38p. 
IBGE - Instituto Brasileiro de Geografia e Estatística. Disponível em: http://www.ibge.gov.br. Acessado em: 02 de fevereiro de 2014.

GAUER, D. A.; MANTOVANI, N. C; SUZANA, C. S. Compatibilidade da arborização urbana no bairro centro no município de Chapada-RS. In: CONGRESSO FLORESTAL ESTADUAL DO RS E $2^{\circ}$ SEMINÁRIO MERCOSUL DA CADEIA MADEIRA, n.11, 2012, Nova Prata-RS. Anais... Nova Prata-RS, 2012.

GONÇALVES, W.; PAIVA, H. N. Árvores para o ambiente urbano. Ação Ambiental, Viçosa, v.9, p.17$19,2000$.

GRAZIANO, T. T.; CASTIGLIONI, F. M.; VASQUES, L. H. Caracterização e análise da arborização das ruas do município de Jaboticabal, SP. Jaboticabal: UNESP-FCAV, 1987. 12 p.

GROSS, A.; DORS, P.; CAMPOS, K. A. de; SILVA, A. C.; HIGUCHI, P. Percepção dos moradores e avaliação da arborização em bairros periféricos na Cidade de Lages, SC. Revista da Sociedade Brasileira de Arborização Urbana, Piracicaba, v.7, n. 2, p.24-36, 2012.

KURIHARA, D. L.; IMAÑA-ENCINAS, J.; de PAULA, J. E. Levantamento da arborização do campus da Universidade de Brasília. Revista Cerne, Lavras, v.11, n.2, p.127-136, 2005.

LANGOWSKY, E.; KLECHOWICJ, N. A. Manual prático de poda e arborização urbana. 3.ed. Cianorte: APROMAC, 2001.42p.

LINDENMAIER, D. S.; SANTOS, N. O. Arborização urbana das praças de Cachoeira do Sul-RS-Brasil: fitogeografia, diversidade e índice de áreas verdes. Séries Botânica, São Leopoldo. n.59, p.307-320, 2008.

LINDENMAIER, D. S.; SOUZA, B. S. P. Arborização viária de Cachoeira do Sul/RS: diversidade, fitogeografia e conflitos com a infraestrutura urbana. Revista da Sociedade Brasileira de Arborização Urbana, Piracicaba, v.9, n.1, p.108ロ122, 2014.

LORENZI, H.; SOUZA, H. M.; MEDEIROS COSTA, J. T. de, CERQUEIRA, L. S. C. de; FERREIRA, E. Palmeiras Brasileiras e Exóticas Cultivadas. Nova Odessa, SP: Instituto Plantarum 2004. 432 p.

LORENZI, H.; SOUZA, H.M. de; TORRES, M.A.V.; BACHER, L.B. Árvores Exóticas no Brasil: madeiras ornamentais e aromáticas. 1.ed. Nova Odessa: Plantarum, 2003. 352p.

LORENZI, H.; SOUZA, H. M.; TORRES, M. A. V.; BACHER, L. B. Árvores Brasileiras: manual de identificação e cultivo de plantas arbóreas nativas do Brasil. 3. ed.1. Nova Odessa/SP: Instituto Plantarum, 2000.

MALAVASI, U. C.; MALAVASI, M. M. Avaliação da arborização urbana pelos residentes - estudo de caso em Marechal Cândido Rondon, Paraná. Revista Ciência Florestal, Santa Maria, v.11, n.1, p.189 $-193,2001$.

MILLER, R. W. Urban Forestry - Planning and Managing Urban Greenspaces. Library of Congress, Second Edition. 1998, 502p.

MILLER, R. W. Urban Forestry: planning and managing urban grenspaces. Upper Saddle River, New Jersey, USA: Prentice Hall, 1996, 502 p. 
MIRANDA, G. P.; FREITAS, M. F.; PASQUALETTO, A.; SANTOS, O. R.; ROSA, I. M. C. R. Diagnóstico da arborização urbana de Goianira-GO. In: III CONGRESSO BRASILEIRO DE GESTÃO AMBIENTAL, 2012. Goiânia-GO. Anais... Goiânia, GO, IBEAS; 2012.

PIVETTA, K. F. L.; FILHO, D. F. S. Arborização Urbana, boletim acadêmico série arborização urbana. Jaboticabal: UNESP/FCAV/FUNEP, 2002. 69P. Disponível em : < http://www.imq.esalq.usp.br/ dfsilva/arborizacao_urbana.pdf > Acesso em: 10 fev. 2014.

RICHTER, C.; PEITER, M. X.; ROBAinA, A. D.; DE SOUZA, A. R. C.; FERRAZ, R. C.; DE DAVID, A. F. Levantamento da arborização urbana pública de Mata/RS. Revista da Sociedade Brasileira de Arborização Urbana, Piracicaba, SP, v.7, n.3, p.88ฤ96, 2012.

RODRIGUES, T. D.; MALAFAIA, G.; QUEIROZ, S. E. E.; RODRIGUES, A. S. de L. Percepção sobre arborização urbana de moradores em três áreas de Pires do Rio - Goiás. Revista de Estudos Ambientais, Itajaí, v. 12, n.2, p.47-61, 2010.

ROPPA, C.; FALKENBERG, J. R.; STANGERLIN, D. M.; BRUN, F. G. K.; BRUN, E. J.; LONGHI, S. J. Diagnóstico da percepção dos moradores sobre a arborização urbana na vila estação colônia - bairro Camobi, Santa Maria - RS. Revista da Sociedade Brasileira de Arborização Urbana, Piracicaba, v.2, n.2, p.11-30, 2007.

SILVA, A. G.; PAIVA, H. N.; GONÇALVES, W. Avaliando a arborização urbana. Viçosa-MG: Aprenda Fácil, 2007. 346p.

SILVA FILHO, D. F. Cadastramento informatizado, sistematização e análise da arborização das vias públicas da área urbana do município de Jaboticabal, SP. 2002.81p. Tese (Doutorado). Universidade Estadual Paulista, Jaboticabal.

STRANGHETTI, V.; SILVA, Z. A. V. Diagnóstico da arborização das vias públicas do município de Uchôa-SP. Revista da Sociedade Brasileira de Arborização Urbana, Piracicaba - SP, v.5, n.2, p.124$138,2010$.

VELASCO, G.D.N. Arborização viária x sistemas de distribuição de energia elétrica: avaliação dos custos, estudo das podas e levantamento de problemas fitotécnicos. 2003, 94p. Dissertação (Mestrado em Fitotecnia) - Escola Superior de Agricultura "Luiz de Queiroz", Universidade de São Paulo, Piracicaba, 2003.

\section{Histórico}

Submetido em: 08/04/2014

Aceito em: 02/10/2014 